\title{
Alternativas actuales a la crisis de la metafísica moderna $^{1}$
}

\author{
JuAN A. NiCOLÁs \\ Universidad de Granada
}

1. La experiencia de nuestro tiempo: crisis de la modernidad

Nos hallamos a finales de siglo inmersos en un profundo "malestar de la cultura", por emplear la expresión freudiana, que viene siendo detectado desde principios del siglo XX. La llamada de E. Husserl "a las cosas mismas", la de C. Marx a transformar el mundo en vez de interpretarlo, la de M. Heidegger a superar el nihilismo de la metafísica científico-técnica, o, en nuestros días, la de G. Vattimo a la asunción de un pensamiento débil, no son sino diversos modos de poner el dedo en la llaga, para señalar que algo muy profundo de nuestra cultura va mal. El diagnóstico prácticamente unánime es el de crisis de toda la etapa histórica llamada 'Modernidad'. Surgen por doquier síntomas de esta crisis: aceleración histórica que hace ineficaces para una generación los valores de la anterior, pérdida de convicciones suficientemente potentes como para instaurar un proyecto coherente de sociedad, desestructuración del saber en parcelas con fines desconectados entre sí, soledad en medio de un mundo hipercomunicado, diferencias económicas y sociales cada vez mayores, fragilidad del sentido individual y colectivo, etc. 
A pesar de la evidencia de la crisis, no resulta fácil determinar con precisión ni qué ha sido la Modernidad, ni qué es exactamente lo que ha perdido vigencia y fuerza de convicción al cabo de varios siglos de desarrollo cultural. Menos claridad puede haber aún en lo relativo a cuál puede ser la alternativa que acabe imponiéndose al final de este periodo de transición. Sin embargo resulta imprescindible abordar estos tres aspectos de la cuestión, puesto que nuestra sociedad, queramos o no, se enfrenta a problemas que nunca antes se habían planteado en la tradición europea, e incluso a ninguna cultura habida en nuestro planeta (por ejemplo, la perspectiva del agotamiento de los recursos energéticos disponibles, o el carácter planetario de algunos de los problemas a resolver).

Un primer acercamiento a la determinación de la Modernidad consiste en identificar el complejo fenómeno de la Ilustración como la linea medular del desarrollo histórico de los últimos cinco siglos en las sociedades europeas y sus ámbitos de influencia. Durante este amplio tramo de tiempo ha habido propuestas filosóficas muy diferentes entre sí. Desde los más restrictivos y exigentes racionalismos hasta los escepticismos de mayor alcance. Se ha reivindicado con fuerza la razón, el sentimiento, la fe, el cuerpo, el trabajo, el lenguaje o la existencia. Pero muchas de esas propuestas han ido quedando en los márgenes de la influencia intelectual y social. Desde este punto de vista, la tradición que más directamente ha modelado el perfil intelectual y social de nuestra sociedad ha sido el llamado movimiento ilustrado. La presunta quiebra de la razón ilustrada no se produce, si es que realmente se ha producido, hasta el siglo que ahora acaba. El romanticismo no transforma la sociedad europea en sus dimensiones políticas, sociales, laborales, cotidianas, productivas, etc. El fruto de su acción crítica no empieza a alcanzar la luz de cierta influencia social en ciertos círculos de ciertas sociedades, transformadamente, hasta la segunda mitad del siglo XX. No podría decirse, honestamente, que vivimos en una sociedad mayoritariamente, en sentido cualitativo, romántica; como no podría decirse que vivamos en una sociedad escéptica o marxista. Lo cual no impide que estos tipos de ideas o planteamientos tenga alguna presencia en nuestro contexto cultural, a veces, relevante en determinados círculos sociales o ámbitos del saber o de la experiencia. Pero no son estas concepciones las que mueven o configuran de modo decisivo las acciones y decisiones sociales, menos aún si se 
tiene en cuenta que cada vez las distintas "sociedades" son menos independientes en su funcionamiento y concepción del mundo.

Siendo así, resulta decisivo abordar la pregunta, nada nueva, de en qué consiste la modernidad ilustrada. Lo específico ahora de la pregunta es que se realiza desde la perspectiva intelectual de comienzos del siglo XXI, es decir, a la vista de los resultados de tres siglos de desarrollo de la concepción ilustrada del mundo y del saber. El objetivo que se pretende abordando esta cuestión es poder entender con precisión el carácter de la crisis actual de la modernidad, los diagnósticos que hay acerca de sus causas y las alternativas que hoy aspiran a orientar e influir en el futuro de nuestra cultura.

\section{2. ¿Qué ha sido de la modernidad ilustrada?}

La Ilustración es un movimiento intelectual y socio-político muy complejo, con características específicas en los diversos países europeos en los que surge con fuerza. Se trata de un proceso que se pone en marcha de manera significativa en el siglo XVI con el Renacimiento y culmina en el siglo XVIII, cuando la autoconciencia de los intelectuales es la de estar en una época de "iluminación". Si hubiera que destacar una característica común de todo este movimiento quizás habría que señalar, el ansia de libertad, tanto en el aspecto teórico del pensamiento como en el aspecto práctico de la acción. Este fue el motor que impulsó a la sociedad en una búsqueda capaz de unificar todo un proyecto socio-político-intelectual, obteniendo además éxitos espectaculares a lo largo de toda su trayectoria.

Conviene resaltar el doble aspecto teórico y práctico de este profundo anhelo, porque ello supone una decisiva diferencia respecto a etapas anteriores, en las que la libertad era fundamentalmente un concepto a hacer jugar en las discusiones y un componente ya dado estructuralmente en la realidad humana. Ahora se trata más bien de algo a alcanzar, algo que hay que trabajarse y ganar, algo por lo que hay que luchar y cuyos límites han de ser empujados siempre más allá. Se introduce así una dimensión práctica que conlleva la transformación no sólo de los métodos y fines del pensamiento, sino también de todas las estructuras sociales (económicas, jurídicas, productivas, científicas, de comunicación, etc.). La actitud ilustrada difiere de la que sostiene paradigmáticamente Descartes, cuando propone mantener la moral establecida mientras se dilucidan las discusiones en vigor plan- 
teadas en el momento. Para ello, elabora una "moral provisional" de carácter netamente conservador, cuya primera máxima era "obedecer las leyes y costumbres de mi país, conservando la religión... y rigiéndome en cualquier otra cuestión por las opiniones más moderadas y más alejadas de todo extremo"2.

El instrumento que en este contexto ha servido de vehículo para llevar adelante todo este movimiento de transformación social e intelectual ha sido la razón, en una peculiar comprensión de la misma. $\mathrm{He}$ aquí un segundo rasgo común a todo ese variado y complejo movimiento histórico que es la Ilustración. Los intelectuales ilustrados depositan su confianza en la razón, convencidos de que a mayor extensión de los ámbitos de aplicación de la razón, en todos sus aspectos teóricos y prácticos, correspondería un mayor progreso general de la $\mathrm{dad}$, tanto en sus aspectos cognoscitivos como morales. Se produce una cierta identificación entre desarrollo racional y progreso humano. Dicho con palabras de F. Bacon, la racionalización de la sociedad ha de contribuir decisivamente a "aliviar y mejorar el estado de la humanidad"3. Este fue el programa planteado por Bacon y asumido por la modernidad, en su trayectoria ilustrada, hasta nuestros días.

La plasmación efectiva del proyecto racionalista ilustrado tiene lugar en el espacio definido por dos coordenadas: en primer lugar, la de una organización política suficientemente flexible y tolerante como para albergar la necesidad-exigencia de libertad de acción. En este línea la evolución social dió lugar a la organización política que es el liberalismo capitalista y la democracia liberal que, para bien o para mal, Europa ha ido exportando a gran parte del resto del mundo. En segundo lugar, el devenir teórico ilustrado se gestó al hilo del desarrollo científico que se venía produciendo desde varios siglos atrás. Esto dió lugar a que la "cultura" ilustrada haya girado en torno a la concepción científica de la racionalidad. Lo cual no significa que todo el ámbito ilustrado haya identificado racionalidad con razón científica. Tan es así, que esta cuestión delimita, justamente, las dos grandes tradiciones filosóficas ilustradas habidas hasta el siglo XX: la empirista y la criticista. Esta doble vía ilustrada puede hallarse ya en el siglo XVIII, pero también en los siglos XIX y XX. Algunas de las polémicas filosóficas más vehementes de las últimas décadas tiene su origen, precisamente, en esta doble tradición ilustrada. 


\section{La doble tradición ilustrada}

Desde su génesis y consolidación en el siglo XVIII ha habido al menos dos concepciones de la razón que se han desarrollado paralelamente. Esta duplicidad explica algunas de las discrepancias importantes formuladas en la actualidad respecto a la caracterización de la tradición ilustrada, respecto a la valoración de sus logros, y respecto a las perspectivas de futuro que cabe pronosticarle.

Los elementos de discusión son fundamentalmente dos: el papel del método en el marco de la racionalidad y la relación entre razón y praxis. Por un lado se ha desarrollado una tradición que considera que lo más propio y específico de la concepción ilustrada de la racionalidad es el método. Este constituye la piedra angular para decidir acerca del grado de racionalidad de un determinado saber. El metodologicismo es una versión actual del criticismo. En esta línea se ha desarrollado la tesis de la unidad de método, ya presente en $\mathrm{R}$. Descartes, y que alcanza desde Hume hasta el racionalismo crítico pasando por el neopositivismo lógico. El método propio de todo saber legítimo y capaz de resolver problemas y, por tanto, de proporcionar progreso es el de las ciencias empíricas (en las diversas versiones que históricamente se han ido elaborando). De ahí que la historia más creativa y valiosa de la Ilustración tienda a identificarse con la historia del desarrollo de la ciencia empírica. El ansia de libertad es interpretada como desarrollo científico, en la linea planteada inicialmente por Bacon. La no adopción por parte de ciertos saberes de esta metodología tiende a interpretarse como resistencias dogmáticas a la implantación del espíritu ilustrado ( $\mathrm{H}$. Albert) o bien, como romántico irracionalismo (M. Bunge).

Este planteamiento resulta especialmente nítido y radical en la obra de M. Bunge. En La relación entre la filosofía y la sociologia caracteriza a la Ilustración como "cientificismo: adopción del enfoque científico para el estudio tanto de la sociedad como de la naturaleza"4. Su comprensión estrictamente positivista de la ciencia le lleva a considerar toda otra tradición, incluido Kant (!), como romanticismo. Éste comprendería desde Rousseau y el idealismo alemán hasta el marxismo, la fenomenología de Husserl, Schopenhauer y Nietzsche y la hermenéutica desde Heidegger hasta el posmodernismo. Esta actitud tan poco matizada le lleva a reducir los problemas gravísimos que la tradición 
ilustrada-positivista tiene hoy planteados a simples "abusos", a pesar de los cuales, la fe en esta razón ha de ser, según él, inquebrantable y la única actitud legítima es la de "seguir hacia adelante"s. El criticismo se identifica con la contrastación empírica y el impulso secularizador con el materialismo. Esta interpretación de la tradición ilustrada es considerada como la representación actual de "la mayor parte de los valores básicos de la vida civilizada contemporánea.

Esta interpretación de la razón ha estado asociada con frecuencia a una determinada concepción de la relación entre la reflexión sobre la praxis y la razón. En concreto tienden a excluir todo lo relativo a la comprensión y la orientación de la conducta humana del ámbito de la racionalidad. Acerca de lo que ha de hacerse, de lo que es justo o injusto, bueno o malo, premiable o castigable no cabe la argumentación racional porque se trata de una parcela de la vida humana transida de sentimientos, irracionalidades, deseos, temores, intereses, etc. Por tanto, en última instancia, nuestra conducta no puede ser racionalmente regulada, porque racionalidad significa metodología científicoempírica. Por ello sólo caben dos actitudes: o bien intentar hacer de la filosofía moral una ciencia con una metodología similar a la de cualquier otra ciencia empírica (H. Albert), o bien reducir el análisis de ese ámbito a una descripción de emociones (D. Hume) o incluso al sinsentido (el primer Wittgenstein, Carnap) o a la simple negación de la existencia de una "razón práctica" (W. Quine).

Se ha desarrollado también una segunda tradición dentro del marco ilustrado tal y como se configuró en el siglo XVIII: la que tiene como punto de referencia a Kant. El ansia de libertad es entendida como autonomía racional. El método de la ciencia queda enmarcado en una teoría de la racionalidad que distingue dos modos de acción correspondientes a dos ámbitos de aplicación: la razón ejerciendo la acción cognoscitiva en el ámbito de la realidad natural, cuyo resultado es la ciencia empírica, y la razón en cuanto que valora y determina lo que ha de hacerse, y cuyo ámbito es la acción humana. Éste último uso de la razón constituye el ámbito de la razón práctica y es el que fija los fines propios del hombre, que han de regir también la acción científica. Para esta tarea diseña el método trascendental, específico de la reflexión filosófica y distinto, por tanto, de los métodos de las ciencias empíricas. El ejercicio de este método de reflexión determina, en 
el caso de Kant, la referencia a la dignidad humana como valor absoluto y los intereses universales de la razón, en cuanto exigibles a todo ser racional.

La tradición kantiana ha dado lugar al neokantismo de la Escuela de Marburgo, una cierta tradición humanista ${ }^{6}$, y llega hasta hoy en la teoría evolucionista del conocimiento y en las diversas variantes de la ética discursiva.

Las dos tradiciones ilustradas aquí distinguidas se han desarrollado paralelamente, con influencias mutuas y elementos comunes. Comparten el impulso y la orientación básicos que en el siglo XVIII recibió la cultura europea hacia la explotación de la razón, hacia el criticismo, la secularización del pensamiento, la búsqueda de la autonomía y de la libertad en todos los órdenes. Ciencia y ética han constituido el binomio en torno al cual han girado las múltiples variantes que a lo largo de dos siglos se han desarrollado. Conjuntamente, constituyen el legado actual de la tradición ilustrada, tal y como ha llegado a las puertas del siglo XXI. Las diferencias significativas en la caracterización, interpretación y uso filosófico de lo que fue el impulso ilustrado explica la multitud de valoraciones que hoy pueden encontrarse ante la tradición ilustrada, incluso entre quienes dicen compartir esa herencia.

En cualquier caso, el conjunto de la orientación racionalista ilustrada de la Modernidad está hoy en cuestión. Tanto el proyecto kantiano como el proyecto empirista de racionalidad han desembocado, por diversas razones, en tal cúmulo de problemas, que el siglo $\mathrm{XX}$ ha sido, en parte, la historia de su revisión, tanto de los fines iniciales como de los logros obtenidos por ahora. Los resultados de tal revisión arrojan balances muy dispares, incluso contrarios, pero en su conjunto visualizan una situación de crisis.

El debate acerca de las causas y configuración de la crisis de la modernidad ilustrada está teñido de cierta experiencia de decepción ante las grandes promesas de tal proyecto. Resulta obvio que no se ha conseguido "aliviar y mejorar el estado de la humanidad" en su conjunto. De ahí que hayan surgido en las últimas décadas diversas propuestas que acogidas bajo el rótulo de "posmodernas", pretenden romper con la trayectoria de la Modernidad. G. Vattimo formula la situación del hombre actual, después de las críticas de Nietzsche y 
Heidegger, como la de "aquél que comprendió que el nihilismo es su única chance. Hoy comenzamos a ser, a poder ser, nihilistas cabales", porque hemos comprendido, al fin, que "del ser como tal, ya no queda nada"'. Por eso, "la biblioteca dentro de la cual habita el hombre tardo-moderno, y dentro de la cual se localiza su experiencia de la verdad, es una biblioteca de Babel"8.

Pero este diagnóstico necesita ser matizado, puesto que no todas las reacciones que actualmente están en discusión pueden ser incluídas dentro de lo que específicamente se ha llamado "posmodernidad". Por ello conviene analizarlas y confrontarlas detalladamente. No todas coinciden exactamente al diagnosticar la situación actual, ni mucho menos en las causas que la han producido, ni menos aún en cuales serían los caminos o alternativas posibles y deseables para salir de la crisis. Las piezas básicas que se manejan en este rompecabezas son la concepción de la razón y su configuración científico-técnica (frente a lo que esa concepción de la razón ha colocado en un segundo plano), la realidad y la posibilidad misma del progreso moral (frente al hecho de la destrucción del hombre por el hombre), y la experiencia del hombre actual con sus múltiples dimensiones (frente a una concepción experimentalista de la experiencia). Con ellas se pretende encontrar luz en la crisis.

\section{Reacciones ante la crisis de la Modernidad}

Se han realizado análisis de las reacciones a la crisis de la Modernidad desde diversas perspectivas. Así por ejemplo, desde la sociología, A. Touraine ha distinguido dos tipos de respuestas, cuya posición sintetiza del siguiente modo: "La primera, la de los posmodernos, afirma que su descomposición es irreversible; la segunda, sostiene que la modernidad puede y debe ser defendida e incluso ampliada" .

Intentaremos aquí hacer un análisis más detallado de la situación. En medio de la enorme y confusa proliferación de críticas, diagnósticos, propuestas, etc., es posible distinguir al menos seis grandes lineas de respuesta ante la crisis de un proyecto instaurado como predominante durante el siglo XVIII, y cuyas raíces se remontan hasta el Renacimiento. Estas seis líneas se pueden agrupar a su vez en tres actitudes básicas. Cada una de ellas se caracteriza por su posición respecto a los tres parámetros siguientes: diagnóstico de la situación actual, valo- 
ración del proyecto de la Ilustración y alternativa para el futuro. Los tipos de reacciones que pueden distinguirse con estos criterios constituyen orientaciones básicas, puesto que, según los casos, hay tanto elementos comunes entre grupos distintos, como diferencias importantes entre autores o corrientes incluídos en un mismo conjunto.

4.1. Reacción continuista. Es la de quienes, con mayor o menor grado de conciencia de la crisis están convencidos de la validez fundamental del conjunto de opciones que supuso el giro ilustrado en la historia de la cultura europea. Por ello los últimos siglos de la misma han ido en la dirección correcta, a pesar de los múltiples y difíciles avatares en que se ha visto envuelta. De ello se deriva que la mejor alternativa es proseguir dentro del marco de la trayectoria realizada hasta ahora, e intentar solucionar desde el interior de dicho marco los problemas, sin duda graves, actualmente planteados.

Esta reacción de continuidad general del proyecto ilustrado puede ejecutarse de diferentes modos. Al menos dos corrientes relevantes hoy pueden ser incluídas en este apartado: el Racionalismo Crítico y el Naturalismo.

4.1.1. Racionalismo Crítico. Movimiento encabezado por Karl Popper y continuado de manera relevante por Hans Albert. El diagnóstico es que la actual es una situación de crisis, pero superable dentro del mismo modelo de racionalidad en el que estamos. Básicamente la trayectoria habida desde el siglo XVIII ha sido correcta, puesto que se ha ido imponiendo la racionalidad científico-técnica-industrial. La crisis se debe precisamente a que el espíritu ilustrado, así entendido, no se ha implantado en grado suficiente.

Por tanto, la valoración del proyecto de la Ilustración es que se trata de un planteamiento válido en lo fundamental, aunque aún no ejecutado. Albert considera su racionalismo crítico como heredero del impulso ilustrado: "Quien se sabe comprometido con la tradición de la Ilustración y del pensamiento crítico puede esperar con tranquilidad el desarrollo de esta controversia" ${ }^{10}$. Ahora bien, Albert destaca de la Ilustración su aspecto criticista, y dentro de éste, sólo sus elementos metodológicos. De ahí su propuesta pancriticista y falibilista, que rechaza cualquier tipo de fundamentación del saber. En su lugar propone el principio de examen crítico, que sustituiría la estrategia del principio de razón suficiente ${ }^{11}$. El problema es que ese espíritu pan- 
criticista no se ha extendido, de hecho, a todos los ámbitos del saber. Albert encuentra múltiples resistencias por parte de determinados saberes a adoptar el rasgo más característico, en su opinión, de lo que es el saber crítico (racional): el método científico. Especialmente relevante en este sentido es su polémica con la Hermenéutica. Ésta se niega a asumir la tesis de la unidad de método basándose en que la relación entre el sujeto del saber y su objeto de investigación es esencialmente distinto en el caso de las ciencias naturales y en el de las ciencias sociales. Este argumento es para Albert un rasgo más de oscurantismo, dogmatismo y resistencia al espíritu ilustrado de transparencia racional.

Respecto a la alternativa para el futuro, el Racionalismo Crítico propone continuar adelante con el proyecto iniciado en la Ilustración, radicalizarlo y llevar la luz de la razón a todos los ámbitos del saber. El ideal sería, por tanto, una sociedad organizada según los cánones del desarrollo crítico-racional, esto es, científico. Se trata pues, de una alternativa continuísta con el modelo imperante hasta ahora, aunque con correcciones internas. Mantiene el impulso que inaugurara Bacon a finales del siglo $\mathrm{XVI}^{12}$.

Pero la estrategia adoptada por Albert para "el esclarecimiento crítico del saber y del obrar en su totalidad, frente al dogma que se pretende inmune a la razón" está ligado a la matriz filosófica del propio racionalismo crítico: el neopositivismo lógico. A pesar de que surge como crítica del mismo, hereda de él al menos su 'metodologicismo' en dos sentidos: la prioridad de método (lo que hace a un saber racional es la utilización de la metodología científica) y la concepción del método como instancia específica y común a toda ciencia, unificadora, por tanto, de todo el saber racional (ideal de ciencia unificada). Dice K. Popper: "Puede describirse la teoría del conocimiento... como una teoría del método empírico" ${ }^{13}$. Así entendido, la distancia respecto al paradigma ilustrado que representa I. Kant es considerable.

4.1.2. Naturalismo. El proyecto de naturalización de la razón tiene ya una larga trayectoria, y ha sido interpretado de múltiples formas. Pueden entenderse en cierto modo como naturalistas desde Nietzsche hasta algunos pragmatistas americanos. Pero actualmente existen dos corrientes naturalistas que pueden situarse en la órbita de la tradición ilustrada, aunque con diferencias entre sí. Se trata de la epistemología 
naturalizada de W. Quine y de la teoría evolucionista del conocimiento, desarrollada por K. Lorenz, G. Vollmer y F.M. Wuketis entre otros $^{14}$.

La continuidad respecto al proyecto original ilustrado se pone de manifiesto si se entiende la naturalización de la razón como una interpretación del impulso secularizador del siglo XVIII. La naturalización es un modo de llevar a cabo la impronta secularizadora propia de la modernidad ilustrada. La naturalización es una versión actual de la secularización. Las dos corrientes mencionadas asumen la transformación de la comprensión del mundo mediante categorías teológicas en una comprensión al hilo de la categorización que ha hecho posible la ciencia moderna. Ambas comparten la confianza en que la razón es el instrumento más adecuado para conseguir el progreso humano y la actitud de que hay que seguir adelante con la trayectoria científicoracional tal y como se ha venido desenvolviendo hasta ahora. Sin embargo, cada uno de estos planteamientos filosóficos están asociados a cada una de las dos tradiciones ilustrada señaladas anteriormente.

A) La epistemología naturalizada de W. Quine. Aunque no sea un tema central para Quine, en algún momento expresa su conciencia de estar situado en continuidad con la problemática ilustrada original. Entiende su proyecto filosófico como "persistencia ilustrada en el problema epistemológico inicial. Es ilustrada, porque reconoce que la impugnación escéptica surge de la ciencia misma y que para enfrentarnos con ella tenemos derecho a usar el conocimiento científico. El epistemólogo antiguo no se dio cuenta de la fuerza de su posición"15. La problemática ilustrada aludida se plantea intensamente con Descartes, y Quine se sitúa en la estela del tratamiento que de la misma hace Hume y posteriormente el neopositivismo lógico. Por tanto, teniendo en cuenta esta delimitación, la valoración que hace Quine del proyecto ilustrado es positiva. Tan positiva, que realmente no hace un problema de la presunta crisis radical de la razón ilustrada. De hecho sus temáticas son típicas de la etapa de configuración de la modernidad: confianza en la razón lógica, la ciencia empírica como expresión privilegiada de la racionalidad, problematicidad del mundo externo, problema del escepticismo, fiabilidad de la sensibilidad y su conexión con el entendimiento y la razón, etc. Una muestra de esta continuidad es la afirmación de que "la epistemología permanece centrada, como siem- 
pre, en la evidencia, y el significado permanece centrado, como siempre en la verificación; y la evidencia es verificación"16. Así, pues, su actitud es continuar la trayectoria ilustrada, en la línea marcada por el empirismo clásico.

En cuanto al diagnóstico de la situación actual, piensa que en nuestra época, como en todas, coexisten fuerzas intelectuales retrógradas y dogmáticas, y otras que favorecen la resolución racional de problemas, y por tanto, el progreso humano. En esta última tendencia sitúa su epistemología naturalizada que, a diferencia del trascendentalismo, representa un avance en la lucha contra el oscurantismo y en la transparencia racional, que es el sentido de la historia en los últimos siglos. Por eso puede decirse que, en algún sentido, "la epistemología y ontología naturalistas han llegado para quedarse"'?

La alternativa para el futuro que plantea Quine consiste en proseguir con el proyecto de naturalización de la razón y su extensión a todos los ámbitos del sabef. Un elemento clave de ese proceso consiste en hacer de la epistemología parte de la psicología y a ésta un capítulo más de la ciencia natural. Retoma bajo esta perspectiva el proyecto originario de Hume en su Tratado sobre la naturaleza bumana, de desarrollar una "ciencia del hombre"; ahora diríamos, hacer del saber acerca del hombre una ciencia. $Y$, al igual que Hume, se privilegia el punto de vista de la psicología para determinar el quehacer de la reflexión filosófica en lo relativo al hecho del conocimiento y su explicación.

B) La teoria evolucionista del conocimiento representada por $\mathrm{K}$. Lorenz, G. Vollmer y F.M. Wuketis entre otros. Esta orientación filosófica permanece dentro de la tradición de la Erkenntnistheorie y por tanto del marco de la ilustración, con el que no quiere romper. Sus intereses y temas son el origen del conocimiento, la relación con la realidad, el saber a priori, el conocimiento sintético, etc. Ahora bien, intenta una transformación de la tradición ilustrada, en particular, de la kantiana desde una perspectiva diferente a la Epistemología naturalizada. Ahora el punto de vista privilegiado (en el sentido de priorizado) ya no es el psicológico, sino el biológico. En particular hay un esfuerzo en incorporar la herencia de Darwin y hacerse cargo realmente y con todas sus consecuencias de su planteamiento evolutivo ${ }^{18}$. Desde esta perspectiva se repiensa el trascendentalismo kantiano que sirve de 
"banco de pruebas" para esta teoría". Se introduce toda una nueva categorización en consonancia con la nueva orientación: evolución, herencia, genética, adaptación, filogénesis, mutación, reproducción diferencial, etc. Con ello se pretende mediar toda la concepción del conocimiento con la variable cronológica, que en la escala de millones de años va dibujando el devenir biológico de la humanidad. Ya no se trata de determinar las condiciones formales que hacen posible el conocimiento, sino las condiciones material-biológicas que lo constituyen. Por ello, el saber formal a priori es ahora un a posteriori filogenético ${ }^{20}$. Se interpreta que los ingredientes biológicos de la realidad humana, en cuanto ineludibles, constituyen su fundamento. Esta es la transformación realizada respecto del trascendentalismo kantiano. Se trata también de una naturalización de la razón en cuanto que intenta explicar todo el ámbito racional desde el punto de vista de la dimensión biológica del ser humano ${ }^{21}$.

Por ello, la evaluación del proyecto original ilustrado es positiva, pero está necesitada de una corrección a la luz del darwinismo. La alternativa planteada consiste en avanzar en la coordinación interdisciplinar entre diversas ciencias (genética, teoría de la evolución, neurociencias, psicolingǘstica, antropología biológica) para ejecutar efectivamente la transformación contenida en el último "giro copernicano" que es el señalado por Darwin"2. Así se completará una representación adecuada de la trayectoria seguida por los seres vivos (desde los más elementales hasta el hombre), y cuyo hilo conductor no es ya la persecución de la verdad sino la eficacia adaptativa. Una vez situados realmente en esta perspectiva, se estará en condiciones de esbozar las posibilidades del sistema cognitivo humano y en consecuencia las posibilidades del hombre en medio del cosmos.

4.2. Reacción rupturista. La reacción anterior pretende seguir adelante con la trayectoria traída hasta ahora, tal y como de becho se ha venido desarrollando; las modificaciones que proponen pretenden ahondar en el espíritu de dicha trayectoria. Pero existe otro tipo de reacciones cuya impronta básica es la de cambiar radicalmente el camino predominante en nuestra sociedad durante los tres últimos siglos. De ahí la calificación de 'rupturista', porque pretende explícitamente romper con algunos elementos esenciales del espíritu de la Ilustración. No obstante, lo primero que hay que señalar es que cualquier ruptura con toda una época sólo puede ser parcial. Por muy radical 
que pretenda ser el giro, en la dialéctica contra algo siempre se heredan ciertos rasgos.

Pueden distinguirse dos tipos de reacciones en la línea mencionada. Una de ellas intenta ir más allá de la modernidad apelando a los productos más heterodoxos que la propia modernidad ha engendrado. Se trata de la llamada Posmodernidad. Pero hay otro intento de romper con la Modernidad que pretende volver a recuperar elementos de ciertas tradiciones anteriores a la Modernidad, y que fueron destruidos precisamente con la aparición de la nueva época. Se trata del giro premoderno que propone actualmente el Comunitarismo.

4.2.1. Ruptura posmoderna. Se trata de una impugnación global de la Modernidad. Si el punto de referencia del grupo anterior era una determinada interpretación de Kant, en este caso se acude a quien pasa por ser el crítico más radical del kantismo, a saber, F. Nietzsche. Los autores más representativos (J.F. Lyotard, G. Vattimo, M. Foucault, J. Derrida, R. Rorty), aunque con diferencias significativas entre sí, se mueven todos en el ámbito filosófico de la hermenéutica, y en particular en una cierta interpretación de la línea NietzscheHeidegger.

En primer lugar, diagnostican la situación actual como un callejón sin salida. El saber se ha deslegitimado ${ }^{23}$. Las contradicciones económicas, políticas, ecológicas, etc. muestran que el proyecto de la Ilustración era equivocado desde su misma raíz. Los problemas a los que ha conducido no representan ninguna distorsión del proyecto original, sino más bien la explicitación de lo que estaba ya contenido dentro. El proyecto original ilustrado era racionalista y explotador del mundo (según esta interpretación). Por ello la metafísica científicotécnica constituye su fruto más elaborado, más influyente y más propio.

Esta metafísica científico-técnica, esencial para la Modernidad, ha de ser superada, aun cuando no se pueda prescindir sin más del hecho de que ha configurado nuestra historia y nuestra experiencia durante los últimos siglos ${ }^{24}$. Se trata, pues, de una cierta ruptura porque pretende acabar, en su superación, con nociones constituvas de la modernidad como las de fundamentación, criticismo, universalidad o verdad. En ello estriba la consumación de la secularización emprendida por la propia modernidad. 
Si en lo referente al diagnóstico existe un acuerdo al menos básico en la necesidad de cambiar de vía, es muy difícil detectar rasgos comunes en las alternativas que proponen autores como J.F. Lyotard, J. Derrida, G. Vattimo o M. Foucault. Se produce una sustitución de la lógica de la identidad por la lógica de la diferencia (Derrida, Lyotard, Vattimo) y la asunción del fragmentarismo tras el "fin de los grandes relatos" (Lyotard, Vattimo), en el marco de la priorización de lo individual frente a cualquier totalidad, sea histórica, sea social, sea epistemológica (Lipovetsky, Foucault). Se acaba con el sujeto sustancial e identificador (Vattimo, Foucault) y se prioriza "lo otro de la razón" (lógico-formal), esto es, la corporalidad, el sentimiento, la voluntad, la sensibilidad (Lyotard). Se transforma la experiencia del tiempo, poniendo el énfasis en el momento presente, en lo fugaz y transitorio, lo contingente, la moda, frente a lo permanente, lo estable lo duradero (Lipovetsky ${ }^{25}$, Lyotard). Se sustituye la fundamentación por la interpretación y la Epistemología por la Hermenéutica (Rorty ${ }^{26}$, Vattimo). Se desestructura o se violenta el discurso lógico-gramatical, bien en su lógica interna, bien en su misma materialidad (Foucault, Derrida ${ }^{27}$ ) para ir más allá de los límites de lo expresable en el discurso racional científico ${ }^{28}$. Se proclama el declive del deber (Lipovetsky) y se lo sustituye por el cuidado de sí (Foucault ${ }^{29}$ ), en la línea de la sustitución de la Ética por la Estética (Vattimo, Lyotard). Finalmente se convierte la Filosofía en retórica, narración, literatura, escritura (Rorty, Lyotard, Derrida).

Todo este conjunto de rasgos más o menos coherentes entre sí muestran al menos un cierto "aire de familia", marcan un ambiente intelectual y experiencial. Independientemente de la trascendencia histórica que tenga finalmente esta "atmósfera cultural", su aportación a la revisión de la Modernidad y a la detección de las insuficiencias que ésta ha arrastrado resulta incuestionable. Para los pensadores de esta orientación quizás el reto estribe en salir del ámbito cultural y afrontar el reto $\operatorname{social}^{30}$, esto es, elaborar una economía, una legislación, una política, una ciencia, etc., coherente con sus principios y viable en las sociedades actuales ${ }^{31}$. De lo contrario, la acusación de conservadurismo que se ha lanzado contra ellos es difícilmente salvable ${ }^{32}$.

4.2.2. Ruptura "premoderna". En la misma línea de romper con el espíritu ilustrado para salvar sus dificultades se encuentra otra reacción cuyo representante más nítido es $\mathrm{A}$. MacIntyre. También $\mathrm{H}$. Jonas 
sostiene algunas tesis que permitirían incluirlo en este grupo ${ }^{33}$. La diferencia principal con el grupo anterior estriba en que la alternativa propuesta se orienta hacia la recuperación de ciertos rasgos de la cosmovisión aristotélica, especialmente en lo que se refiere al ámbito ético. De ahí que esta corriente pueda calificarse de premoderna.

El diagnóstico de la situación actual es el de que se ha perdido el sentido de la pertenencia a una comunidad concreta cuyos valores la sociedad afirma y defiende, y con ello se ha perdido también el punto de referencia básico de la identidad personal. Así, vivimos en una situación de "politeísmo axiológico", de escisión entre razón sustancial y razón formal, y, por último, de emotivismo moral, resultado de la pérdida de fundamento de la experiencia moral socialmente configurada y asumida.

Respecto al proyecto ilustrado que ha desembocado en esta situación, se piensa que es irreparable, porque estaba equivocado desde su concepción. No se trata de que se haya degenerado, sino que en su raíz misma hay una pérdida irrecuperable (desde dentro del mismo modelo) de algunos elementos esenciales de la moralidad humana ${ }^{34}$. La Ilustración puso el énfasis en un universalismo que pretendía detectar aquello que todo hombre, en cuanto ser racional, tiene en común y le hace ser humano. Esta base común habría de servir de fundamento para justificar la reflexión ética y para criticar la praxis sociopolítica. Pero este planteamiento se ha configurado como un universalismo abstracto y formal, y como una moral de deberes. El precio pagado por ello ha sido la pérdida de fuerza integradora en la comunidad concreta y sus valores, la pérdida de identidad individual y la pérdida de vigencia eficaz de la realidad social. Se ha debilitado la experiencia moral y su capacidad de justificación objetiva.

La alternativa que se propone para modificar la situación es apelar a instancias externas a la propia tradición ilustrada. En particular, se reivindica la filosofía práctica de Aristóteles y su moral de virtudes ${ }^{35}$. Se trataría de recuperar una racionalidad sustancial (frente a la racionalidad formal moderna), la teleología (frente al funcionalismo moderno) y la comunidad concreta, con sus experiencia y sus tradiciones (frente al universalismo crítico de la modernidad). Con ello se recuperarían las virtudes como hábitos de la comunidad y la identidad individual diseñada en ese marco. De lo que se trataría pues, sería de inte- 
grar y de crear comunidad, más bien que de mantener la actitud crítica (y por tanto, relativamente distante) y la autodeterminación autónoma que caracteriza a la Ilustración. La consecuencia teórica de este planteamiento es el rechazo de cualquier dimensión utópica del pensamiento (potencialmente crítico) ${ }^{36}$ y de cualquier posibilidad de fundamentación última (puesto que toda creencia, todo valor y toda justificación está ligada a una determinada comunidad histórica, cultural, política, etc.).

4.3. Reacción transformadora. Existe un tercer grupo de reacciones ante la crisis de la Modernidad que, por un lado, son conscientes de la necesidad de cambios significativos en el rumbo actual de nuestra cultura y nuestra sociedad, pero, por otro lado, tienen también la firme convicción de que la Modernidad, tal y como se ha desarrollado, ha hecho contribuciones a la autoconciencia de la humanidad, a su condición socio-política y a sus posibilidades de desarrollo científico y moral, que resultan irrenunciables. De ahí que propugnen una reforma desde dentro, que, por un lado, se diferencia de quienes pretenden seguir ahondando en la misma línea seguida hasta ahora, sin cambios de fondo; y por otro, se distancia también de quienes pretenden renunciar a lo esencial de la herencia que nos ha legado la Ilustración. Se trata de opciones transformadoras de la Modernidad.

En esta orientación se pueden distinguir dos corrientes, que guardan diferencias significativas entre sí.

4.3.1. Transformación conservadora. Esta corriente está constituída por los llamados neoconservadores. Su representante más prototípico es $\mathrm{D}$. Bell ${ }^{37}$, y podría incluirse en este mismo grupo P. Berger ${ }^{38}$.

Para estos autores, el diagnóstico de la situación actual es el de crisis por degeneración de la modernidad cultural: de la ética del trabajo en la que se gestó la Ilustración se ha pasado, por su propio impulso, a una ética hedonista. Esto choca con otros aspectos de las sociedades capitalistas, que siguen funcionando en términos de productividad, industrialización, rendimiento y competencia. Esta situación hace que resulte cada vez más difícil el funcionamiento de las sociedades capitalistas, y lleva a la extensión de ciertos rasgos capitalistas a sociedades aún no "colonizadas".

Siendo así, la posición ante el proyecto originario de la Ilustración es considerarlo válido, pero con necesidad de reajustes importantes en 
el ámbito de la razón práctica. El problema de la Modernidad no está en su origen, sino en su desarrollo último. Junto a lo que se considera un valioso desarrollo técnico (que no es preciso frenar ni reorientar) se ha producido una atrofia de la razón moral y un exceso de reivindicación de la autonomía individual. El resultado de todo ello es la disgregación social y el hundimiento de los valores de la burguesía capitalista.

La alternativa es, pues, proseguir la modernidad social (progreso científico-técnico) y corregir la modernidad cultural (remoralización) con el objetivo de legitimar el sistema económico-social legado por el último capitalismo: el liberalismo económico y político. Para ello se propone como elemento valioso la religión, que cuenta con gran capacidad de generar cohesión social y adhesión a las costumbres y valores morales instaurados en las tradiciones culturales.

Esta posición plantea varios problemas. En primer lugar, la interpretación conservadora que se hace del papel de la religión, ignorando todo su potencial crítico. En segundo lugar, la tesis de la independencia entre las esferas social y cultural. Más bien parece que éstas ni funcionan separadamente ni son separables. Las distorsiones en el ámbito cultural no son independientes del aparato económico-político. Por ello difícilmente se puede asumir el intento de mantener uno intacto y cambiar el otro. En cualquier caso, sería más bien la organización económica y política la que ha dado lugar a la estructura moral e ideológica dominante en las sociedades de capitalismo avanzado (Habermas).

4.3.2. Transformación crítica. Esta alternativa es desarrollada principalmente por J. Habermas, K.O. Apel, y en cierto modo A. Wellmer. En rasgos fundamentales prosiguen la línea de crítica a la Modernidad marcada por la primera generación de la Escuela de Frankfurt. Comparten con el grupo anterior la convicción de que la Modernidad ha de "dirigirse en una dirección diferente", aunque contiene elementos irrenunciables. La crisis de la situación actual se debe a una distorsión y reducción del proyecto ilustrado. En el proyecto de racionalidad esbozado por Kant los diversos ámbitos de la razón estaban subordinados a los fines racionales (universalizables) que determina la razón en su ámbito práctico. Esto se ha transformado al cabo de los siglos en una escisión de hecho entre razón teórica y razón práctica, y en un 
predominio de la razón estratégica (instrumental) sobre todos los ámbitos del saber y del obrar humanos. Así, han quedado sometidas la razón comunicativa y la razón emancipatoria.

Frente a quienes pretenden arreglar los males de nuestra sociedad incidiendo exclusivamente en el ámbito de la modernidad cultural (neoconservadores), Habermas señala y reclama la interrelación de ese nivel con el de la modernidad social ${ }^{39}$. La escisión entre ciencia, moral y arte ha de ser recompuesta desde el mundo de la vida. Éste ha de ser capaz de generar instituciones que limiten la racionalidad instrumental dentro de su ámbito propio, y libere otros ámbitos de la vida humana de semejante yugo. Las relaciones entre las personas no pueden fructificar si se someten a cánones puramente estratégicos.

Por su parte, K.O. Apel pone el acento en una concepción de la razón y de la fundamentación de tipo trascendental, en sentido kantiano, corregida por la semiotización del giro lingüístico, la incorporación de la dimensión pragmática y la ruptura de la metafísica de la presencia, procedente de la hermenéutica ${ }^{40}$. Por último, $\mathrm{A}$. Wellmer se mueve en el borde mismo de la Modernidad, al tomar como punto de referencia la crítica a la Modernidad de Adorno y confrontarla con el proyecto habermasiano ${ }^{41}$.

Sería sin duda filosóficamente productivo analizar el origen y justificación de la confianza de Habermas en que el mundo de la vida tiene capacidad regeneradora del saber y de moralidad, frente a las limitaciones adquiridas, de hecho, por el proyecto ilustrado. Quizás la postura de Habermas exprese más bien una necesidad sentida, que iría en la línea de recuperar aquello que la trayectoria de la racionalidad estratégico-técnica ha ido dejando en los márgenes, o simplemente en segundo plano ${ }^{42}$. En este sentido tal vez habría que re-equilibrar el proyecto ilustrado en su estado actual con algunos de los elementos que sus críticos exigen. Junto a la promoción del criticismo, la autonomía, la solidaridad, la universalidad y el desarrollo técnico, que constituyen lo más valioso del legado ilustrado, habría que incorporar el sentido y el valor de la comunidad y la individualidad, recuperar el papel de la corporalidad y la sensibilidad como constitutivo de la intelección humana, complementario del aspecto lógico-formal, reivindicar la fuerza y el poder de la realidad como contrapunto de una razón que prioriza el logos y sus mediaciones, repensar la experiencia del tiempo, en par- 
ticular de la aceleración histórica, etc. En estos sentidos habría que impulsar el pathos ilustrado para hacerlo viable hoy.

A la vista de los diferentes diagnósticos y alternativas a la Modernidad ilustrada, queda claro, al menos, que las promesas de la Ilustración no se han realizado y que este modelo, de hecho, está en cuestión. La experiencia del hombre actual es de confusión, crisis, apatía, carencia de convicciones fuertes y de fundamentos, etc. Sin prejuzgar ninguno de los diagnósticos anteriores, se impone como una de las tareas urgentes, un análisis detenido de aquel tipo de planteamientos que han asumido y afrontado con más radicalidad la profunda crisis de nuestra cultura moderna, y se han esforzado por buscar alternativas: las filosofías hermenéuticas. En otros lugares me he ocupado de quienes pretenden con más énfasis continuar el espíritu de la Ilustración, en debate precisamente con la Hermenéutica, a saber, el Racionalismo Crítico ${ }^{43}$.

\section{Desfondamiento de la experiencia: nihilismo hermenéutico}

La hermenéutica se ha convertido en el portavoz e intérprete de una dimensión esencial de la experiencia de gran parte de los ciudadanos de las sociedades industrialmente desarrolladas de finales de siglo. Siguiendo la estela de Heidegger, se diagnostica el desfondamiento de la experiencia, porque hay experiencia de desfondamiento. El dictamen heideggeriano de nihilismo late en esta interpretación de la experiencia propia, individual y colectiva, actual e histórica. Se convierte en objetivo de la reflexión filosófica la asunción del nihilismo como única posibilidad, y como condición de nuestra libertad. El intento hermenéutico de superar los problemas de la "metafísica de la presencia" ha acarreado consigo la pérdida del vigor y de la raíces vivificantes que se pueden detectar también en la experiencia. El hecho de que todo dato de conciencia sea ya interpretado, no implica (como han pretrendido algunas posiciones hermenéuticas) que en la experiencia de la presencia haya sólo interpretación, y por tanto, distanciamiento respecto a aquello que se hace presente. La superación de la metafísica de la presencia no implica necesariamente la salida nihilista que propone, entre otros, G. Vattimo.

¿Qué duda cabe de que las corrientes hermenéuticas no normativas han captado parte del "espíritu" intelectual y experiencial de ciertas 
capas sociales de algunas zonas del mundo más desarrolladas? Como en todas las épocas de crisis, se vive en la sensación de que el suelo se hunde a nuestros pies, de que no hay a donde agarrarse, de que "todo lo sólido se desvanece en el aire". Se trata, sin duda, de una experiencia auténtica.

Pero este hecho puede interpretarse en términos de que el objetivo es instalarse en él (convertirnos en "nihilistas cabales" y "vivir una experiencia fabulizada de la realidad"44), o bien como una apelación urgente a la búsqueda de alternativas. La primera de las opciones resulta sencillamente inmoral, puesto que supone permanecer acríticamente en una situación de injusticia para con la mayor parte de la humanidad. En este punto es decisivo el hecho de la dependencia de la hermenéutica "posmoderna" respecto a la Modernidad. Esta alternativa no es ni planteable de modo razonable en sociedades que no han pasado por la experiencia de la Ilustración. Lo cual no significa que toda sociedad haya de pasar por el mismo tipo de modernización, pero sí ayuda a relativizar y situar en sus justos términos el alcance de la propuesta posmoderna.

Para explorar la segunda vía, ha de comenzarse por una revisión del análisis que la hermenéutica ha hecho desde Heidegger tanto de la historia y evolución de nuestra cultura, como de la actual situación social, política, moral, etc. Naturalmente, la valoración de dicho diagnóstico no cabe en los límites de un trabajo como éste. Sí pueden indicarse hechos como el de que teniendo en cuenta la transformación heideggeriana también se han desarrollado hermenéuticas normativas que pretenden retener el espíritu crítico de la modernidad ilustrada; o hechos como el de que a estas alturas existen fuentes de experiencia procedentes de los márgenes de nuestra cultura hiperdesarrollada técnicamente que pueden constituir reservas de innovación moral y cultural; o como el hecho de que en el análisis de la constitución de la experiencia se tenga en cuenta fundamentalmente las dimensiones histórica y lingüística, pero se ignora la dimensión de realidad, irreductible a las anteriores, y que constituye un elemento insoslayable del análisis (se apela con ello al elemento fenomenológico aún presente en Heidegger, que sus seguidores, en general, no han explorado ${ }^{45}$ ).

La tarea filosófica planteada es la de asumir el giro heideggeriano, hacer un balance de los desarrollos a los que ha dado lugar, realizar 
una evaluación detallada de la situación actual de las diversas corrientes ilustradas y confrontarlas con las anteriores. Ésta ha de ser una fuente de replanteamientos e iniciativas de cara a abordar el futuro. Naturalmente, esta tarea no está por comenzar. Mucho se ha discutido sobre ella. Quizás quienes mejor situadas estén para abordar la cuestión clave de reganar un apoyo firme de nuestra acción al hilo de la experiencia individual y social del momento sean las fenomenologías de orientación realista. Entre las filosofías del logos (ilustradas) y las de la disolución del fundamento (hermenéuticas), aquéllas han esbozado un camino que urge recorrer.

\section{NOTAS}

1. Este trabajo es resultado de una investigación subvencionada por el Ministerio de Educación y Cultura (DGICYT, PS95/0238). Se completa con otro titulado "Noología y/o hermenéutica", Concordia, 38 (2000), 89-108.

2. R. Descartes, Discurso del método, trad. G. López Quintás, Alfaguara, Madrid, 1981, p. 18 (AT, VI, 23).

3. Cfr. F. Bacon, La gran restauración, ed. M.A. Granada, Alianza Editorial, Madrid, 1985, 2 parte, "Novum Organum", LXXIII, p. 127; también LXVI, p. 119.

4. M. Bunge, La relación entre filosofia y sociologia, EDAF, Madrid, 2000 (ed. orig., 1999), pág. 208.

5. Ibíd., págs. 223-4.

6. Cfr. J. Conill, "Ilustración", en M. Moreno, Diccionario de pensamiento contempord́neo, San Pablo, Madrid, 1997, págs. 668-72.

7. G. Vattimo, El fin de la modernidad, Gedisa, Barcelona, 1995, p. 23.

8. G. Vattimo, Mds alld de la interpretación, Paidós, Barcelona, 1995, p. 139.

9. Cfr. Alain Touraine, Crttica de la Modernidad, F.C.E., Buenos Aires, 1994, p. 178.

10. H. Albert, Tratado sobre la razón critica (ed. orig., 1968), Sur, Buenos Aires, 1973, p. 182.

11. Para una valoración detallada de los aspectos epistemológicos de la propuesta de H. Albert puede verse J.A. Nicolás, "El fundamento imposible en el racionalismo crítico de H. Albert", Sistema, 88 (1989), 117-127; y "¿Es el racionalismo crítico un relativismo?", Dialogo Filosófico, 7 (1987), 14-30; Estudios Filosóficos, 36/102 (1987) es un número dedicado monográficamente al análisis y evaluación de la filosofía de este autor.

12. Cfr. F. Bacon, op. cit., CXXVII, p. 180-1.

13. K. Popper, La lógica de la investigación cientifica (ed. orig., 1935), Tecnos, Madrid, $6^{2}$ reimp., Madrid, 1982, p. 39.

14. Cfr. F. Broncano, "La naturalización de la razón", en L. Olivé (ed.), Racionalidad epistémica, Trotta-CSIC, Madrid, 1995, págs. 223-243.

15. W. Quine, Las raices de la referencia, Alianza, Madrid, 1988, pág. 17 (ed. orig., 1974). 
16. W. Quine, "La naturalización de la epistemología" en La relatividad ontológica y otros ensayos, Tecnos, Madrid, 1974, pág. 118 (ed. orig., 1969).

17. F. Broncano, art. cit., p. 239.

18. Cfr. G. Vollmer, Evolutionäre Erkenntnistheorie, Hirzel, Stuttgart, 7_ed., 1998.

19. Sobre la relación entre teoría evolucionista del conocimiento y la filosofía trascendental pueden consultarse los siguientes trabajos: J. Pacho, ¿Naturalizar la razón?, Siglo XXI, Madrid, 1995 (esp. caps. 6-7 y 13-14); W. Lütterfelds (ed.), Transzendentale oder evolutionäre Erkenntnistheorie?, Frankfurt, 1987.

20. Cfr. J. Pacho, "El a priori del saber y saber del a priori en las teorias evolucionista y trascendental", en E. García, J. Muñoz (comps.), La teoría evolucionista del conocimiento, Ed. Complutense, Madrid, 1999, págs. 93-111.

21. En nuestro idioma es interesante la presentación de conjunto de la teoría evolucionista del conocimiento realizada por N. Ursúa, Cerebro y conocimiento: un enfoque evolucionista, Anthropos, Barcelona, 1993.

22. Cfr. J. Pacho, N. Ursúa, Razón, evolución, ciencia, DDb, Bilbao, 1990, págs. 3950.

23. Cfr. J.F. Lyotard, La condición posmoderna, Cátedra, Madrid, 1989.

24. Sobre este punto puede verse la matizada posición al respecto de G. Vattimo, "Heidegger y la superación de la modernidad" en Filosofía, Política, Religión (ed. Ll. Alvarez), Ediciones Nobel, Oviedo, 1996, pp. 31-46. Del mismo autor, El fin de la modernidad, Ed. Gedisa, Bacelona, 1995, esp. pp.99-159 (ed. orig., 1985); y "Reconstrucción de la racionalidad", en $M_{-}$s alla de la interpretación, PP. 147-161 (ed. orig., 1992).

25. Cfr. G. Lipovetsky, La era del vació, Anagrama, Barcelona, 1988 (ed. orig., 1983).

26. Cfr. R Rorty, La filosofía y el espejo de la naturaleza, Cátedra, Madrid, 1989 (ed. orig., 1979).

27. Cfr. J. Derrida, De la gramatología, Siglo XXI, Buenos Aires, 1970 (ed. orig., 1967).

28. En esta línea se encuentra la obra de J.L. Rodríguez, Verdad y escritura, Anthropos, Barcelona, 1994. En ella busca modos de manifestación de la verdad en diversos tipos de lenguajes no ligados a la lógica gramatical: poesía, fantasía, metáforas, e incluso el silencio. Son modos de revelación de la verdad, donde se entremezclan pasiones, deseos, gustos, miedos, etc., con la materialidad de la escritura. El conjunto expresa la tragedia del hombre apresado entre las rejas de sus lenguajes: "Reconocer el origen y vivir aún en el territorio del deseo de la Verdad y de su decir es la tragedia" (p. 106).

29. Cfr. M. Foucault, La inquietud de st, Siglo XXI, Madrid, 1987 (ed. orig., 1984).

30. Cfr. F. Jameson, Teoría de la posmodernidad, Trotta, Madrid, 1996.

31. Cfr. J. Conill, "Para pensar la posmodernidad", en El enigma del animal fantástico, Tecnos, Madrid, 1991, pp. 271-329.

32. Cfr. J. Habermas, "Modernidad versus posmodernidad", en J. Picó (comp.). Modernidad y posmodernidad, Alianza, Madrid, 1988, págs. 87/102; y J.M. Mardones, "El neoconservadurismo de los posmodernos", en G. Vattimo et al., En tomo a la posmodernidad, Anthropos, Barcelona, 1990, pp. 21-40.

33. Concretamente la reivindicación de ciertos rasgos aristotélicos. Cfr. H. Jonas, $E l$ principio de responsabilidad, (ed. orig., 1979), Herder, Barcelona, 1995. 
34. Cfr. A. McIntyre, Tras la virtud (ed. orig., 1984), Ed. Crítica, Barcelona, 1987, esp. Pp. 56-106.

35. Cfr. Op. cit., pp. 185-207.

36. Cfr. H. Jonas, op. cit., caps. V.5, V.6 y VI.

37. Cfr. D. Bell, El fin de las ideologias, Tecnos, Madrid, 1964 (ed. orig., 1960); Las contradicciones culturales del capitalismo, Alianza, Madrid, 1977 (ed. orig., 1976); Las ciencias sociales desde la Segunda Guerra Mundial, Alianza, Madrid, 1984 (ed. orig., 1982).

38. Cfr. P. Berger, Pirámides de sacrificio, Sal Terrae, Santander, 1979; Rumor de angeles, Herder, Barcelona, 1975.

39. Cfr. J. Habermas, "Modernidad versus posmodernidad", art. cit.

40. Cfr. K.O. Apel, La transformación de la filosofia, Taurus, Madrid, 1985 (ed. orig.); Teoria de la verdad y ética del discurso, Paidós, Barcelona, 1991 (ed. orig. 1987).

41. Cfr. A. Wellmer, Finales de partida: la modernidad irreconciliable, Cátedra, Madrid, 1996 (ed. orig., 1993); Sobre la dialéctica de modernidad y postmodernidad, Visor, Madrid, 1993 (ed. orig., 1985).

42. Sobre este punto puede verse A. Cortina, Ética sin moral, Tecnos, Madrid, 1990, esp. cap. 4.

43. Cfr. arts. citados en nota 11.

44. Cfr. G. Vattimo, El fin de la modernidad, págs. 23 y 32.

45. Cfr. J. Conill, "Hermenéutica antropológica de la razón experiencial", en D. Blanco et al. (eds.), Discurso y realidad, Trotta, Madrid, 1994, págs. 131-143; R. Rodriguez, "Introducción", en G. Vattimo, Más allá de la interpretación, págs. 9-32. 